Provided for non-commercial research and educational use only. Not for reproduction or distribution or commercial use.

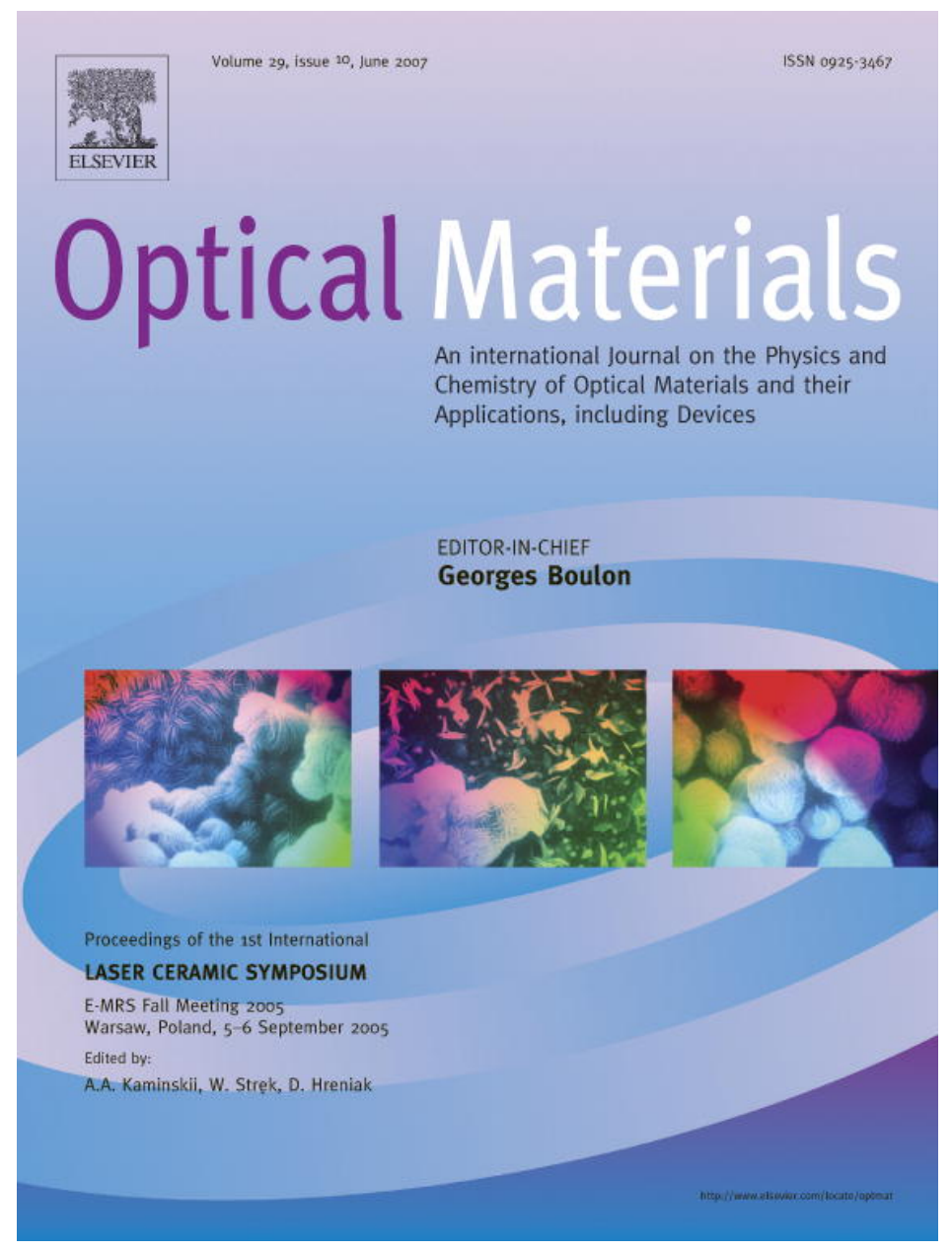

This article was originally published in a journal published by Elsevier, and the attached copy is provided by Elsevier for the author's benefit and for the benefit of the author's institution, for non-commercial research and educational use including without limitation use in instruction at your institution, sending it to specific colleagues that you know, and providing a copy to your institution's administrator.

All other uses, reproduction and distribution, including without limitation commercial reprints, selling or licensing copies or access,

or posting on open internet sites, your personal or institution's website or repository, are prohibited. For exceptions, permission may be sought for such use through Elsevier's permissions site at: 


\title{
Synthesis and optical properties of powders of lutetium and yttrium double phosphates-doped by ytterbium
}

\author{
M. Guzik ${ }^{\text {a }}$ J. Legendziewicz ${ }^{\text {a,* }}$, W. Szuszkiewicz ${ }^{\text {b }}$, A. Walasek ${ }^{\text {a }}$ \\ ${ }^{a}$ University of Wrockaw, Faculty of Chemistry, 14 F. Joliot-Curie, PL-50-383 Wrockaw, Poland \\ ${ }^{\mathrm{b}}$ Institute of Chemistry, Wroctaw University of Economics, 118/120 Komandorska, PL-53-345 Wroctaw, Poland
}

Received 16 March 2006; received in revised form 24 April 2006; accepted 26 April 2006

Available online 8 September 2006

\begin{abstract}
This contribution is devoted to the new ytterbium-doped alkali metal lutetium double phosphates and their structural and spectroscopic characterisations. The absorption, emission and excitation spectra have been measured at 4, 10 and $293 \mathrm{~K}$ in the VUV to IR range. The results have been compared with the analogous yttrium phosphates. The luminescence spectra of the double phosphates have been recorded using various excitation lines, including the synchrotron radiation. The low temperature absorption and emission spectra in the region of the ${ }^{2} \mathrm{~F}_{7 / 2} \rightarrow{ }^{2} \mathrm{~F}_{5 / 2}$ transition together with the IR spectra have been used to assign the electronic and vibronic components. Detailed analysis of the $\mathrm{Yb}^{3+}$-doped sodium lutetium double phosphates has been performed to determine the energy levels in these hosts and to compare their optical behaviour with analogous sodium yttrium double phosphates. The emission and excitation spectra have been investigated using synchrotron radiation and the origin of the emission has been analysed proving that the emission occurs from the charge transfer state.
\end{abstract}

(C) 2006 Elsevier B.V. All rights reserved.

Keywords: Emission; Absorption; CT emission; Yttrium double phosphates; Lutetium double phosphates

\section{Introduction}

Since the development of the InGaAs diode laser much attention has been focused on $\mathrm{Yb}^{3+}$-doped materials. The luminescence originating from the transitions between the manifold of Stark-splitted levels of the $\mathrm{Yb}^{3+}$ ion in different crystals with $\mathrm{Yb}^{3+}$ has been extensively studied in relation to the possible laser applications. $\mathrm{The} \mathrm{Yb}^{3+}$ ion can create laser action in the IR range around $1000 \mathrm{~nm}$ and has several advantages when compared to the $\mathrm{Nd}^{3+}$-doped systems already employed in various laser materials. The intense and broad $\mathrm{Yb}^{3+}$ absorption lines are well suited for the IR laser diode pumping [1].

There is no concentration quenching and the small Stokes shift reduces the thermal loading of the material

\footnotetext{
* Corresponding author. Tel.: +48 713204 300; fax: +48 713282348 .

E-mail address: j1@wchuwr.chem.uni.wroc.pl (J. Legendziewicz).
}

during laser operation and increases the laser efficiency. The ytterbium-doped lasers have longer emission lifetime than the $\mathrm{Nd}^{3+}$-doped materials, which enhances the storage capacity and reduces quantum defects between the absorption and emission processes. All these properties of $\mathrm{Yb}^{3+}$ indicate that the trivalent ytterbium seems to be more promising that the trivalent neodymium.

On the other hand, together with the intraconfigurational $4 \mathrm{f}-4 \mathrm{f}$ transitions, also a broad absorption band (called CT) can be observed for the trivalent ytterbium ion. In 1978, Nakazawa first observed the luminescence due to the reverse process of the CT absorption and reported this phenomenon for the $\mathrm{Yb}^{3+}$ ion in phosphate and oxysulfate lattices [2].

Until recently the CT luminescence of the rare earth ions has not been investigated extensively. The interest in $\mathrm{Yb}^{3+}$ was renewed by the discovery of possible application of compounds containing this lanthanide in the real-time spectroscopy of solar neutrinos [3]. A comprehensive study 
of the $\mathrm{Yb}^{3+} \mathrm{CT}$ luminescence in phosphates, borates, aluminates, oxysulfides, oxyhalogenides, oxides and fluorides matrices has been carried out [4]. Also, in the red phosphor used in fluorescent tubes $\left(\mathrm{Y}_{2} \mathrm{O}_{3}: \mathrm{Eu}^{3+}\right) \mathrm{UV}$ radiation is efficiently absorbed by a transition to the charge transfer state of the $\mathrm{Eu}^{3+}$ ion.

The properties of alkali rare earth double phosphates of the $\mathrm{M}_{3} \mathrm{RE}\left(\mathrm{PO}_{4}\right)_{2}$ type have been studied as photoluminescent materials by several authors [5-14]. These double phosphates have their host absorption edge at a rather short wavelength which make them suitable as the host lattices for various luminescent materials including laser devices.

This work is devoted to the structural and spectroscopic characteristics of new ytterbium-doped sodium lutetium double phosphates. The results obtained have been compared with the same type of yttrium double phosphates which have been already reported in our earlier paper [13].

It has been reported by several authors that materials with $\mathrm{Lu}^{3+}$ instead of $\mathrm{Y}^{3+}$-codoped with $\mathrm{Yb}^{3+}$ ions reduced the solarisation effects and improved the lasing performance $[1,15]$.

\section{Experimental}

\subsection{Materials and methods}

$\mathrm{Na}_{3} \mathrm{Lu}_{1-x} \mathrm{Yb}_{x}\left(\mathrm{PO}_{4}\right)_{2}$ and $\mathrm{Na}_{3} \mathrm{Y}_{1-x} \mathrm{Yb}_{x}\left(\mathrm{PO}_{4}\right)_{2} \quad(x=0.1$ and 0.2 ) were prepared via the procedure described before [12]. Briefly, they were obtained by a solid state reaction at $900{ }^{\circ} \mathrm{C}$ in air for $12 \mathrm{~h}$ with the stoichiometric amounts of $\mathrm{Na}_{3} \mathrm{PO}_{4}$ and the mixed lutetium-ytterbium phosphate hydrate $\left(\mathrm{Lu}_{1-x} \mathrm{Yb}_{x}\left(\mathrm{PO}_{4}\right)_{2} \cdot x \mathrm{H}_{2} \mathrm{O}\right)$ or yttrium-ytterbium phosphate hydrate $\left(\mathrm{Y}_{1-x} \mathrm{Yb}_{x}\left(\mathrm{PO}_{4}\right)_{2} \cdot x \mathrm{H}_{2} \mathrm{O}\right)$, respectively. The post-reaction treatments were carried out in the platinum crucible at $1400{ }^{\circ} \mathrm{C}$ in the air atmosphere. The samples were doped with 10 and $20 \mathrm{~mol}$ per cent of the trivalent ytterbium. The starting chemical compounds were commercially available ultra-pure powders, to avoid impurity centers. The absorption, emission and FT-infrared data, the elementary analysis results as well as the X-ray diffraction and thermal analysis data proved the composition and phase purity of the expected compounds.

The X-ray powder diffraction (XRD) patterns were recorded at room temperature for $2 \theta=1-120^{\circ}$ with a DRON-1 type diffractometer $\left(\mathrm{CuK}_{\alpha}\right.$ radiation; $\lambda=$ $1,5418 \AA$ ) and a Stoe IPDS diffractometer (University of Cologne, Germany; $\mathrm{MoK}_{\alpha}$ radiation; $\lambda=0,7107 \AA$ ). The crystalline phases were determined by the comparison of the registered patterns with the International Center for Diffraction data (ICDD)-Powder Diffraction Files (PDF). The thermogravimetric analysis (TG) and (DTA) were performed in the range of temperatures $40-1400{ }^{\circ} \mathrm{C}$ on a Setsys $16 / 18$.

Since the salts are hygroscopic they had to be handled in dry conditions. All operations with the samples were performed in a dry box.

\subsection{Spectroscopic measurements}

The absorption measurements were performed using a Cary-Varian 500 scanning spectrophotometer equipped with an Oxford CF1204 helium flow cryostat between 4 and $293 \mathrm{~K}$ in the $850-1050 \mathrm{~nm}$ spectral region. The pellets used for the absorption and emission measurements were prepared under $0.7 \mathrm{MPa}$ pressure. The oscillator strengths of the $4 \mathrm{f}-4 \mathrm{f}$ transitions of the ytterbium ions were calculated by integration of the Gauss-Lorentz shaped bands by using an ICH-10 program $[16,17]$. The studies of the
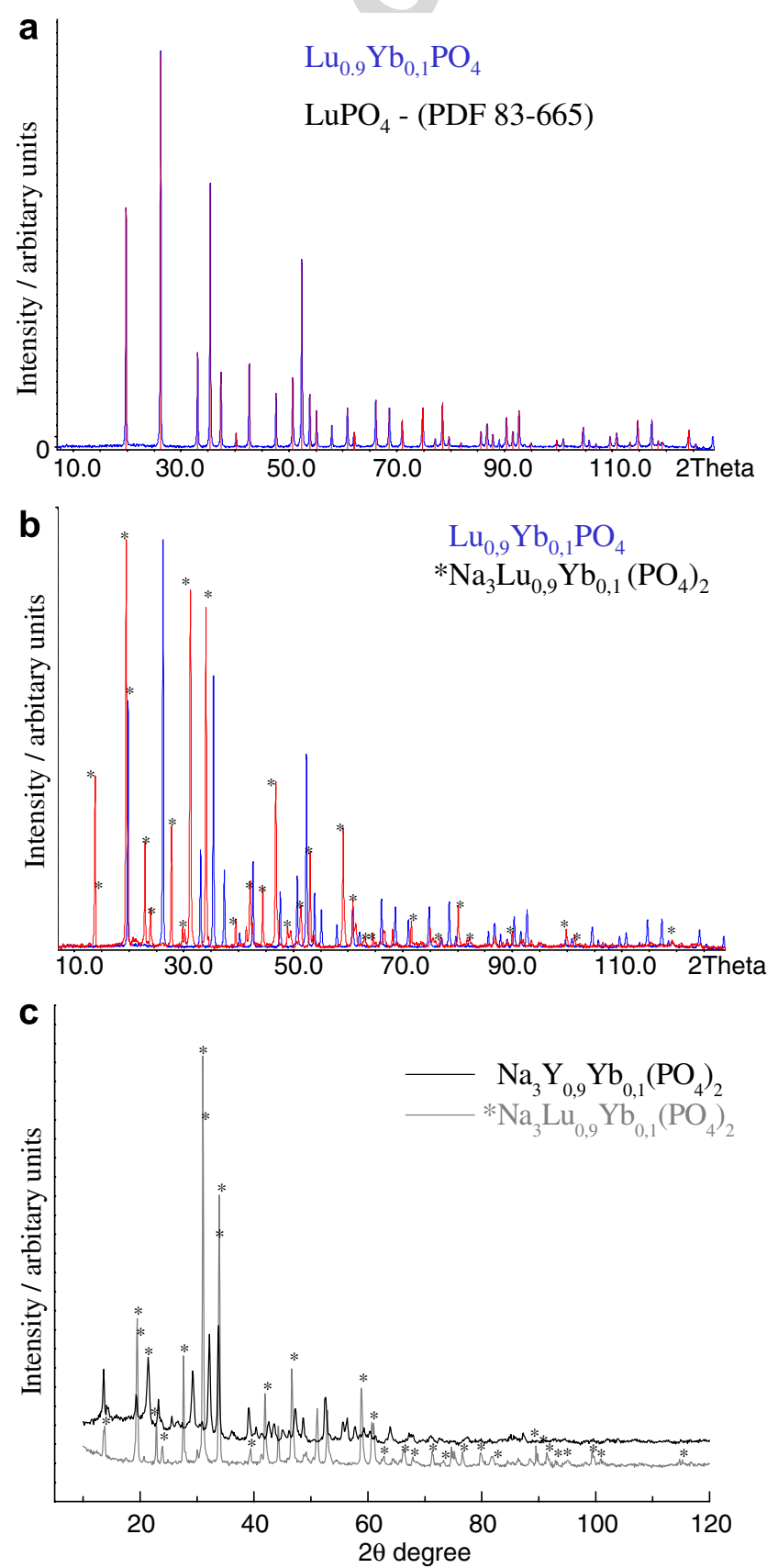

Fig. 1. XRD diagrams of $\mathrm{LuPO}_{4}\left(\mathrm{PDF}\right.$ 83-665) and $\mathrm{Lu}_{0.9} \mathrm{Yb}_{0.1} \mathrm{PO}_{4}$ (a) $\mathrm{Lu}_{0.9} \mathrm{Yb}_{0.1} \mathrm{PO}_{4}$ and $\mathrm{Na}_{3} \mathrm{Lu}_{0.9} \mathrm{Yb}_{0.1}\left(\mathrm{PO}_{4}\right)_{2}$ (b) $\mathrm{Na}_{3} \mathrm{Y}_{0.8} \mathrm{Yb}_{0.2}\left(\mathrm{PO}_{4}\right)_{2}$ and $\mathrm{Na}_{3} \mathrm{Lu}_{0.9} \mathrm{Yb}_{0.1}\left(\mathrm{PO}_{4}\right)_{2}$ (c) powdered samples. 
luminescent characteristics of the investigated compounds were performed on a SUPERLUMI station at the HASYLAB (DESY, Hamburg, Germany) with a synchrotron radiation excitation. The luminescence and luminescence excitation spectra were investigated at 10 and $293 \mathrm{~K}$ in a wide energy range $(80-1100 \mathrm{~nm})$.

The infrared spectra of the powdered samples (FT-IR) were recorded in the spectral range $40-4000 \mathrm{~cm}^{-1}$ on a Fourier-transform spectrometer Bruker IFS 88 with a resolution of $0.1 \mathrm{~cm}^{-1}$. The powdered samples were mixed with $\mathrm{KBr}$ and then pressed.

\subsection{Structural considerations}

The synthesis of the $\mathrm{Na}_{3} \mathrm{Y}\left(\mathrm{PO}_{4}\right)_{2}$ double phosphates using the solid state reaction mainly leads to the formation of only one phase of the expected double phosphates [13]. The structures of these compounds have been studied by several authors [7-14]. The alkali double phosphates crystallize with various structures depending on the alkali metal and the ionic radius of the lanthanide ion. The sodium yttrium double phosphates doped with ytterbium ions crystallize in the orthorhombic system (space group $P b c 2_{1}, \# 29, Z=24$ ) [7-9] which is distorted from the hexagonal glaserite $\left(\mathrm{K}_{3} \mathrm{Na}\left(\mathrm{SO}_{4}\right)_{2}\right)$ structure. As both $\mathrm{YPO}_{4}$ and $\mathrm{LuPO}_{4}$ have the same crystal structure (tetragonal, zircon-type) we expected that the analogous compound of $\mathrm{Na}_{3} \mathrm{Lu}\left(\mathrm{PO}_{4}\right)_{2}: \mathrm{Yb}^{3+}$ would be isostructural with $\mathrm{Na}_{3} \mathrm{Y}\left(\mathrm{PO}_{4}\right)_{2}: \mathrm{Yb}^{3+}$. However, as it can be seen in the $\mathrm{X}$-ray diffraction patterns of both compounds (Fig. 1) they are similar but not identical. Diffractograms of $\mathrm{Na}_{3} \mathrm{Lu}\left(\mathrm{PO}_{4}\right)_{2}$ and $\mathrm{Na}_{3} \mathrm{Y}\left(\mathrm{PO}_{4}\right)_{2}$ are not only shifted but also additional new lines can be observed. From this it can be assumed structural modification and supposed that $\mathrm{Na}_{3} \mathrm{Lu}\left(\mathrm{PO}_{4}\right)_{2}: \mathrm{Yb}^{3+}$ crystallizes with a crystal structure different from the orthorhombic yttrium compounds. Since knowledge about the structure of lutetium double phosphates sodium salt is still limited and the structure of this compound is unknown, the detail analysis of compounds on the successive steps of synthesis was carried out and presented.

\section{Results and discussion}

The investigations of $\mathrm{Yb}^{3+}$ and others $\mathrm{Ln}^{3+}$ ions-doped sodium and rubidium yttrium double phosphates have been undertaken by us because these compounds are efficient hosts for lasing materials [12-14]. To our knowledge, this contribution presents for the first time results of spectroscopic studies of the properties of $\mathrm{Yb}^{3+}$ in the double alkali double phosphates matrix involving $\mathrm{Lu}^{3+}$ instead of $\mathrm{Y}^{3+}$

Our investigations of the $\mathrm{Eu}^{3+}, \mathrm{Nd}^{3+}$ and $\mathrm{Pr}^{3+}$ double phosphates sodium salts have revealed that the active ions may occupy two or even more sites [12-14]. Such investigations can help to clarify the optical properties of the $\mathrm{Yb}^{3+}$ double phosphates because our knowledge concerning this issue is still limited.

The low and room temperature absorption spectra of $\mathrm{Na}_{3} \mathrm{Lu}\left(\mathrm{PO}_{4}\right)_{2}: \mathrm{Yb}^{3+}$ show the typical $\mathrm{Yb}^{3+}$ ions ${ }^{2} \mathrm{~F}_{7 / 2} \rightarrow$ ${ }^{2} \mathrm{~F}_{5 / 2}$ transition at around $1000 \mathrm{~nm}$ and they seem to be less complex than those of $\mathrm{Na}_{3} \mathrm{Y}\left(\mathrm{PO}_{4}\right)_{2}: \mathrm{Yb}^{3+}$. The main bands in the absorption spectra consist of the three electronic Stark components of the ${ }^{2} \mathrm{~F}_{5 / 2}$ excited level situated at 10244, 10515 and $11045 \mathrm{~cm}^{-1}$ for $\mathrm{Na}_{3} \mathrm{Y}\left(\mathrm{PO}_{4}\right)_{2}: \mathrm{Yb}^{3+}$ and 10252,10555 and $11008 \mathrm{~cm}^{-1}$ for $\mathrm{Na}_{3} \mathrm{Lu}\left(\mathrm{PO}_{4}\right)_{2}: \mathrm{Yb}^{3+}$, with the total CF splitting of $801 \mathrm{~cm}^{-1}$ and $756 \mathrm{~cm}^{-1}$ for the yttrium and lutetium salts, respectively. This result is surprising when one compares the ionic radii of the $\mathrm{Y}^{3+}$ and $\mathrm{Lu}^{3+}$ ions. The splitting of the excited ${ }^{2} \mathrm{~F}_{5 / 2}$ state is similar to that of the oxide materials (about $793 \mathrm{~cm}^{-1}$ ) [18] and is much larger than in the fluoride hosts (about $420 \mathrm{~cm}^{-1}$ ) [1]. The bands in the absorption spectra of $\mathrm{Na}_{3} \mathrm{Lu}\left(\mathrm{PO}_{4}\right)_{2}: \mathrm{Yb}^{3+}$ at room as well as at low temperatures are a little blueshifted in comparison to the yttrium salts (see Fig. 2). This could be caused by the disordering of the lutetium double phosphates lattice when the $\mathrm{Lu}^{3+}$ ions are substituted by the larger $\mathrm{Yb}^{3+}$ ions (the ionic radii: $\mathrm{Y}^{3+}-1.04$, $\mathrm{Lu}^{3+}-0.988, \mathrm{Yb}^{3+}-0.998 \AA$ ). On the other hand, the decrease of temperature to $4 \mathrm{~K}$ leads to a broadening of the line which also could confirm some disordering of the $\mathrm{Na}_{3} \mathrm{Lu}\left(\mathrm{PO}_{4}\right)_{2}: \mathrm{Yb}^{3+}$ crystal structure.

The absorption spectra at low temperatures, especially in the case of the yttrium salts, are more complex than the spectra observed at room temperature (RT). In the spectra of $\mathrm{Nd}^{3+}, \mathrm{Eu}^{3+}$ and $\mathrm{Pr}^{3+}$ double phosphates the presence of a larger number of lines than expected for one site indicates more sites of the active ions in the double phosphates [12-14]. In contrast to that, in the ytterbium double phosphates the interpretation of the spectra is not so easy. The additional components observed in the spectra

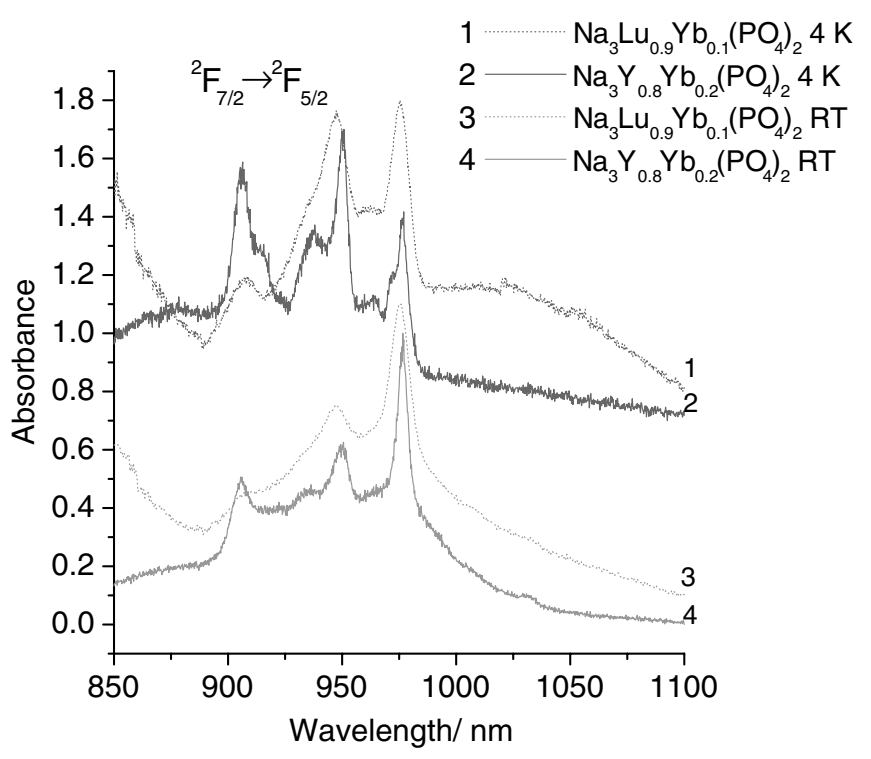

Fig. 2. The absorption spectra of $\mathrm{Na}_{3} \mathrm{Y}_{0.8} \mathrm{Yb}_{0.2}\left(\mathrm{PO}_{4}\right)_{2}$ and $\mathrm{Na}_{3} \mathrm{Lu}_{0.9} \mathrm{Yb}_{0.1}\left(\mathrm{PO}_{4}\right)_{2}$ at 4 and $293 \mathrm{~K}$. 


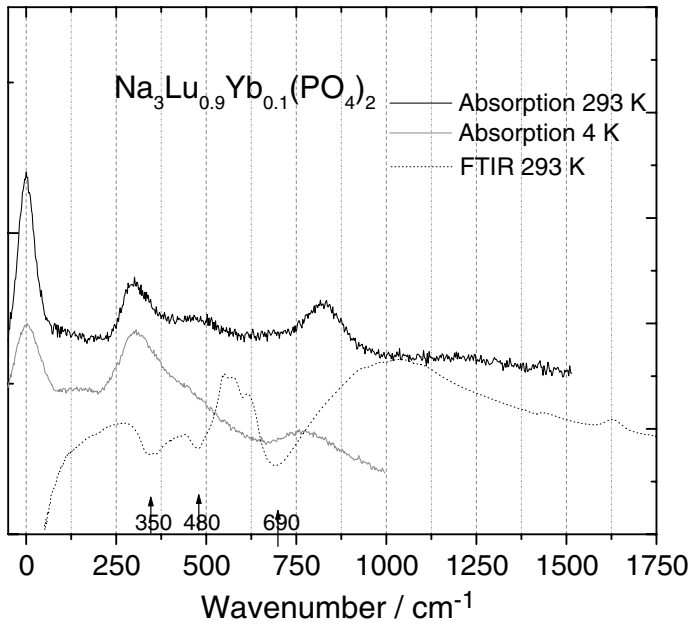

Fig. 3. The absorption spectra at 4 and $293 \mathrm{~K}$ with superposition of IR spectra of $\mathrm{Na}_{3} \mathrm{Lu}_{0.9} \mathrm{Yb}_{0.1}\left(\mathrm{PO}_{4}\right)_{2}$.

at $4 \mathrm{~K}$ can be due to the strong electron-phonon coupling, much stronger for the $\mathrm{Yb}^{3+}$ ion than for $\mathrm{Eu}^{3+}$ one. Thus, the additional lines and also the broadening of the bands could have a vibronic and/or a cooperative origin. In order to distinguish between the electronic and the vibronic transitions we have compared the absorption and emission spectra at low temperature with the IR spectra. The vibronic components corresponding to the IR active vibrations are present at around 350, 480 and $690 \mathrm{~cm}^{-1}$ for $\mathrm{Na}_{3} \mathrm{Lu}_{0.1} \mathrm{Yb}_{0.9}\left(\mathrm{PO}_{4}\right)_{2}$ (Fig. 3), similarly as for $\mathrm{Na}_{3} \mathrm{Y}_{0.8^{-}}$ $\mathrm{Yb}_{0.2}\left(\mathrm{PO}_{4}\right)_{2}$ [13]. Thus, some components localised at these energies (relatively to the 0 -phonon lines) are of a vibronic origin. The decrease of the intensity with lowering of the temperature both for the yttrium salt $\left({ }^{*} \mathrm{P}=4366\right.$ at $\mathrm{RT}$ to 2039 at $4 \mathrm{~K})$ and the lutetium salt $\left({ }^{*} \mathrm{P}=1122\right.$ at $\mathrm{RT}$ to 813 at $4 \mathrm{~K}$ ) is the result of the depopulation of the Stark components of the ${ }^{2} \mathrm{~F}_{7 / 2}$ ground state splitted by the crystal field. This dependence could also confirm the vibronic origin of the electronic transitions components.

The emission spectra were mainly measured using the synchrotron radiation. The emission spectra of $\mathrm{Yb}^{3+}$ was expected to reveal four electronic levels of the ground ${ }^{2} \mathrm{~F}_{7 / 2}$ state, as a consequence of the symmetry reduction induced by the crystalline Stark splitting. However, as we can see from Fig. 4 the situation was more complicated. Additional sharp lines were observed in the luminescence spectra of the yttrium double phosphate at $10 \mathrm{~K}$ around $10225 \mathrm{~cm}^{-1}(978 \mathrm{~nm})$. The band is splitted into two components in contrast to the lutetium salt. Similarly as in the absorption spectra, the shift toward the higher energy in the case of the lutetium double phosphates is also visible in the emission spectra. The absorption and emission spectra of $\mathrm{Na}_{3} \mathrm{Y}\left(\mathrm{PO}_{4}\right)_{2}: \mathrm{Yb}^{3+}$ and $\mathrm{Na}_{3} \mathrm{Lu}\left(\mathrm{PO}_{4}\right)_{2}: \mathrm{Yb}^{3+}$ at low and room temperature are presented in Fig. $5 \mathrm{a}$ and $5 \mathrm{~b}$.

\footnotetext{
${ }^{*} \mathrm{P}=$ integrated intensities of the absorption bands.
}

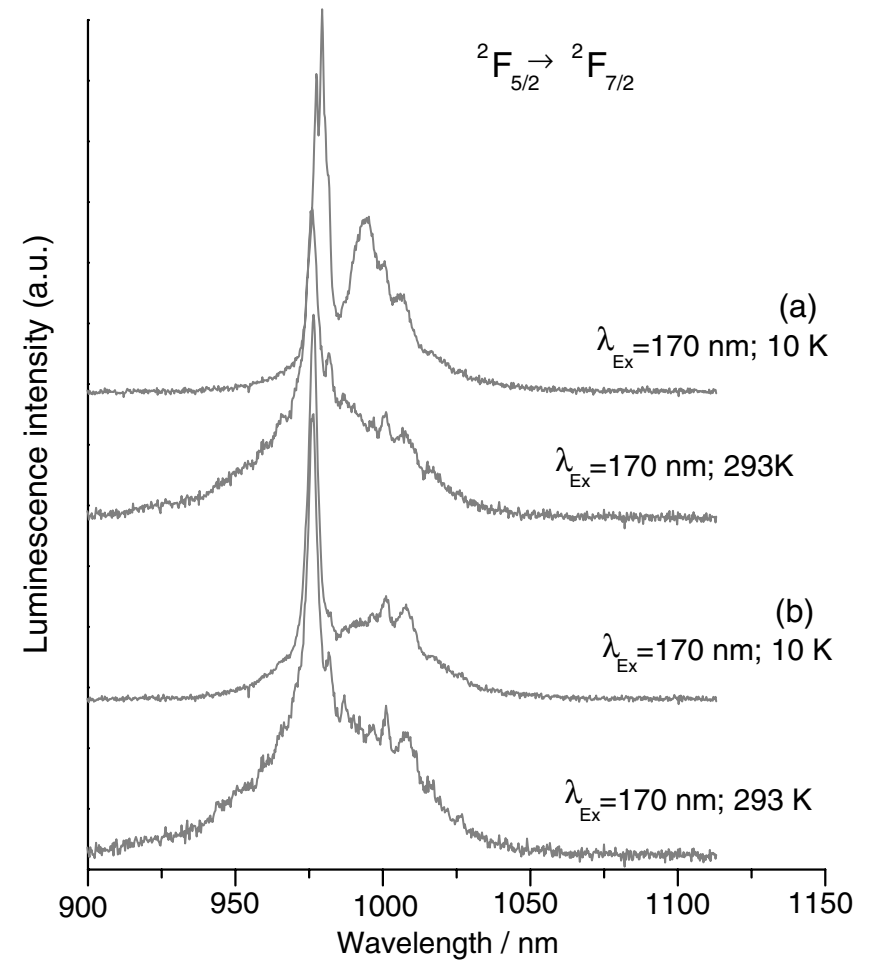

Fig. 4. The emission spectra of $\mathrm{Na}_{3} \mathrm{Y}_{0.8} \mathrm{Yb}_{0.2}\left(\mathrm{PO}_{4}\right)_{2}$ (a) and $\mathrm{Na}_{3} \mathrm{Lu}_{0.9} \mathrm{Yb}_{0.1}\left(\mathrm{PO}_{4}\right)_{2}$ (b) at 10 and $293 \mathrm{~K}$ with synchrotron radiation excitation at $170 \mathrm{~nm}$.

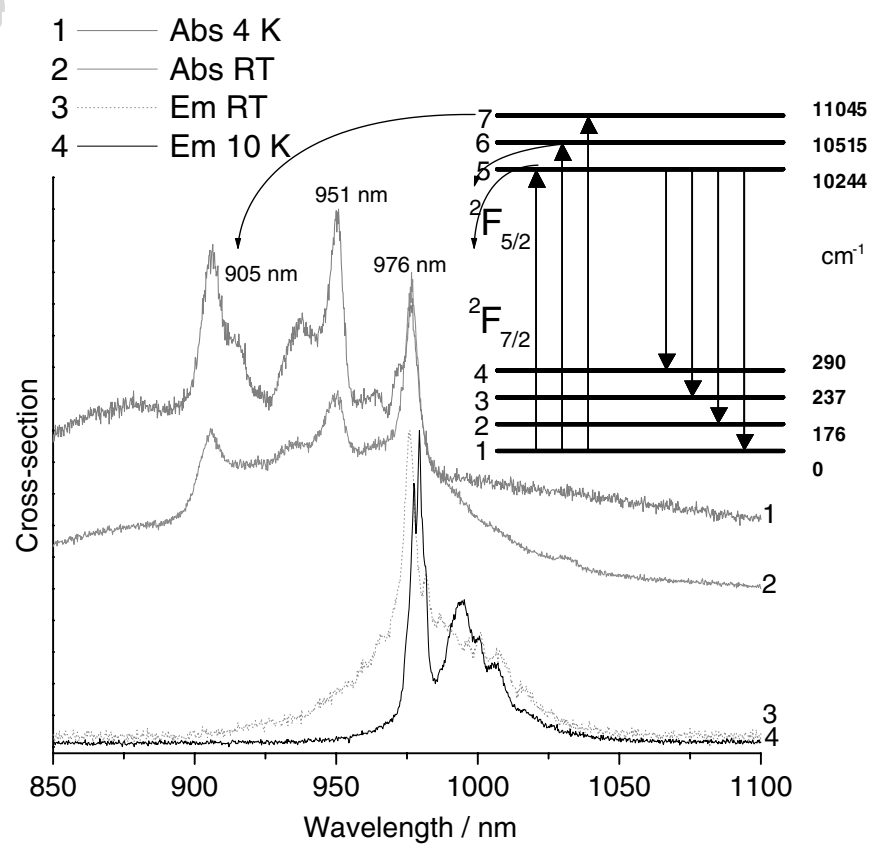

Fig. 5a. The absorption spectra and emission spectra of $\mathrm{Na}_{3} \mathrm{Y}_{0.8} \mathrm{Yb}_{0.2}\left(\mathrm{PO}_{4}\right)_{2}$ under synchrotron radiation $170 \mathrm{~nm}$ at low and room temperature.

The zero-phonon line is clearly observed around the $1 \rightarrow 5$ and $5 \rightarrow 1$ transitions. The total $\mathrm{CF}$ splittings of 


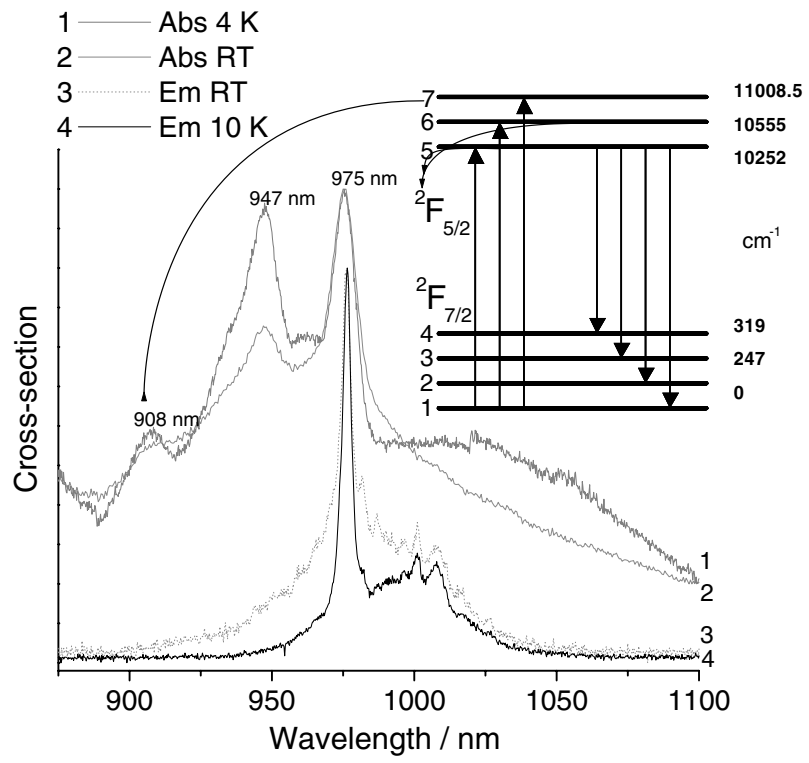

Fig. 5b. The absorption spectra and emission spectra of $\mathrm{Na}_{3} \mathrm{Lu}_{0.9} \mathrm{Yb}_{0.1}\left(\mathrm{PO}_{4}\right)_{2}$ under synchrotron radiation $170 \mathrm{~nm}$ at low and room temperature.

the ${ }^{2} \mathrm{~F}_{7 / 2}$ ground level are 319 and $290 \mathrm{~cm}^{-1}$ for the lutetium and yttrium salts, respectively (see Insert in Fig. 5).

In the spectra of the compounds under investigation, the reabsortion for the zero-phonon line around $980 \mathrm{~nm}$ has not been observed. However, the strong overlap of the absorption and emission spectra originating from the transitions between the four Stark components of the ground ${ }^{2} \mathrm{~F}_{7 / 2}$ and the three components of the excited ${ }^{2} \mathrm{~F}_{5 / 2}$ state of $\mathrm{Yb}^{3+}$ is well known for various matrices $[1,19]$. The relationship between the total $\mathrm{CF}$ splitting of the ${ }^{2} \mathrm{~F}_{7 / 2}$ and ${ }^{2} \mathrm{~F}_{5 / 2}$ levels allows to suggest the energy level scheme for both kinds of the investigated samples.

The $\mathrm{f}-\mathrm{f}$ emission spectra presented in this paper have been measured with the synchrotron radiation excitation. To explain all the phenomena in the studied systems it has been necessary to collect the emission spectra of the ytterbium compound using also the IR excitation.

Together with the narrow $4 \mathrm{f}^{n}-4 \mathrm{f}^{n}$ intraconfigurational transitions for the trivalent lanthanides ions also a broad band can be observed in the high energy region which corresponds to the $4 \mathrm{f}^{n-1} 5 \mathrm{~d}-4 \mathrm{f}^{n}$ or change transfer (CT) transitions. Until now only few papers have discussed the CT luminescence. As $\mathrm{Yb}^{3+}$ does not have the high-energy $4 \mathrm{f}$ states as the $\mathrm{Eu}^{3+}$ ion does and only the excited ${ }^{2} \mathrm{~F}_{5 / 2}$ State (4f) of the $\mathrm{Yb}^{3+}$ ion is located at $10000 \mathrm{~cm}^{-1}$ above the ground state ${ }^{2} \mathrm{~F}_{7 / 2}$, there is a large energy difference $\left(39000 \mathrm{~cm}^{-1}\right)$ between the CT sate and the highest $4 \mathrm{f}$ state. Thus, for $\mathrm{Yb}^{3+}$ the reverse process of the CT absorption can be observed. The charge transfer luminescence for orthophosphates and sulfates was first reported by Nakazawa in 1978 [2]. A very extensive study of $\mathrm{Yb}^{3+}$ doped into various inorganic matrices has been performed by the Meijerink group [4,21].

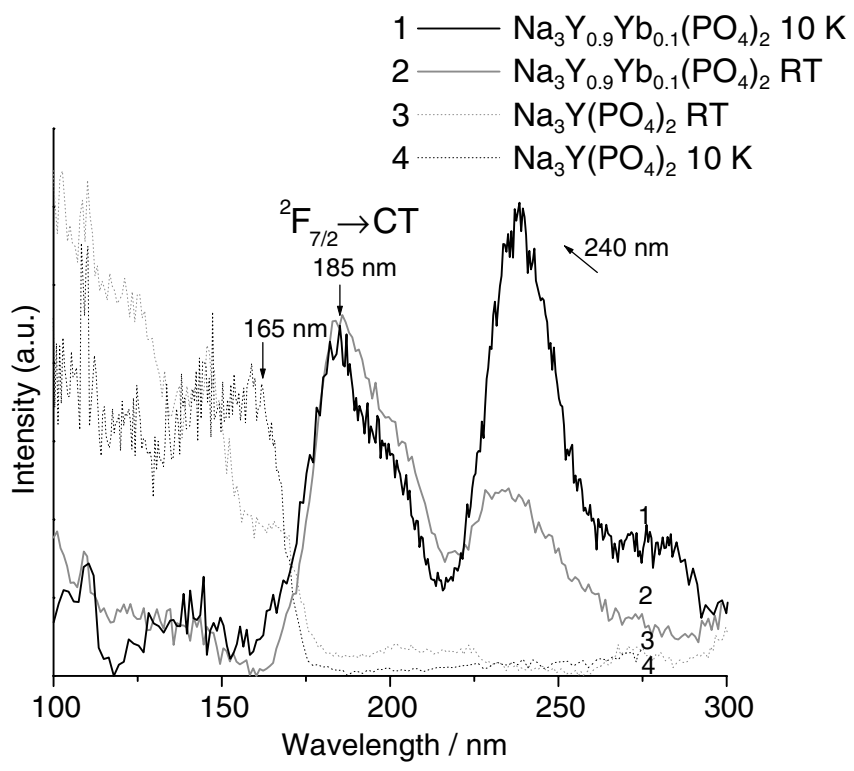

Fig. 6. The excitation spectra of the $\mathrm{Na}_{3} \mathrm{Y}\left(\mathrm{PO}_{4}\right)_{2}$ host lattice and of $\mathrm{Na}_{3} \mathrm{Y}\left(\mathrm{PO}_{4}\right)_{2}$ doped with $10 \mathrm{~mol}^{\%} \mathrm{Yb}^{3+}$ at 10 and $293 \mathrm{~K}, \lambda_{\text {det }}=375 \mathrm{~nm}$.

To identify the $\mathrm{Yb}^{3+} \mathrm{CT}$ luminescence, besides the spectra of the $\mathrm{Yb}^{3+}$-doped systems, the luminescence of the host lattice is necessary for comparison. The VacuumUV spectroscopy has been used to investigate the electronic structure of the materials. The excitation spectra at room and low temperatures have been used to determine the hosts absorption edges of the yttrium and lutetium double phosphates as well as those of the matrices doped with the ytterbium ions. The lutetium and yttrium double phosphates have the absorption edge at about $165 \mathrm{~nm}$ (see Fig. 6) which is typical for these kinds of matrices. It has been reported that the edge of the absorption for phosphates, double phosphates and cyclotetraphosphates is located in the range $140-168 \mathrm{~nm}[4,6,20]$. Our results are in good agreement with this data. The excitation emission spectra of $\mathrm{Yb}^{3+}$-doped $\mathrm{Na}_{3} \mathrm{Lu}\left(\mathrm{PO}_{4}\right)_{2}$ and $\mathrm{Na}_{3} \mathrm{Y}\left(\mathrm{PO}_{4}\right)_{2}$ with $\lambda$ detection at $375 \mathrm{~nm}$ show the strong absorption bands with the maxima at $185 \mathrm{~nm}$ and $240 \mathrm{~nm}$, respectively. The first absorption band can be assigned to the ${ }^{2} \mathrm{~F}_{7 / 2} \rightarrow \mathrm{CT}$ transition of the $\mathrm{Yb}^{3+}$ ion in $\mathrm{Na}_{3} \mathrm{Y}\left(\mathrm{PO}_{4}\right)_{2}$. As it has been mentioned, the high energy $(170 \mathrm{~nm})$ excitation source has been used. Fig. 7 shows the emission spectra of the $\mathrm{Yb}^{3+}$-doped $\mathrm{Na}_{3} \mathrm{Y}\left(\mathrm{PO}_{4}\right)_{2}$ and $\mathrm{Na}_{3} \mathrm{Y}\left(\mathrm{PO}_{4}\right)_{2}$ matrices. Two broad bands peaked at $296 \mathrm{~nm}\left(33783 \mathrm{~cm}^{-1}\right)$ and $469 \mathrm{~nm}$ $\left(21324 \mathrm{~cm}^{-1}\right)$ can be seen. If we deselect from emission given by these doped samples, emission given by the matrix (defect centres), the energy of the second $\mathrm{Yb}^{3+}$ emission band can be located at approximately $420 \mathrm{~nm}$ $\left(23809 \mathrm{~cm}^{-1}\right)$. It fits quite well as the energy difference between ${ }^{2} \mathrm{~F}_{5 / 2}$ and ${ }^{2} \mathrm{~F}_{7 / 2}\left(33783-23809=9974 \mathrm{~cm}^{-1}\right)$. The energy of the CT state localized by us corresponds well with the CT state energy calculated from the Jørgensen relationships $\sigma=\left[\chi\left(\mathrm{O}^{2-}\right)-\chi\left(\mathrm{Yb}^{3+}\right) 30 \mathrm{kK}\right]$ based on the optical electronegativity of the oxide atom of the phosphate $\mathrm{PO}_{4}^{3-}$ group and the ytterbium ions [22]. 


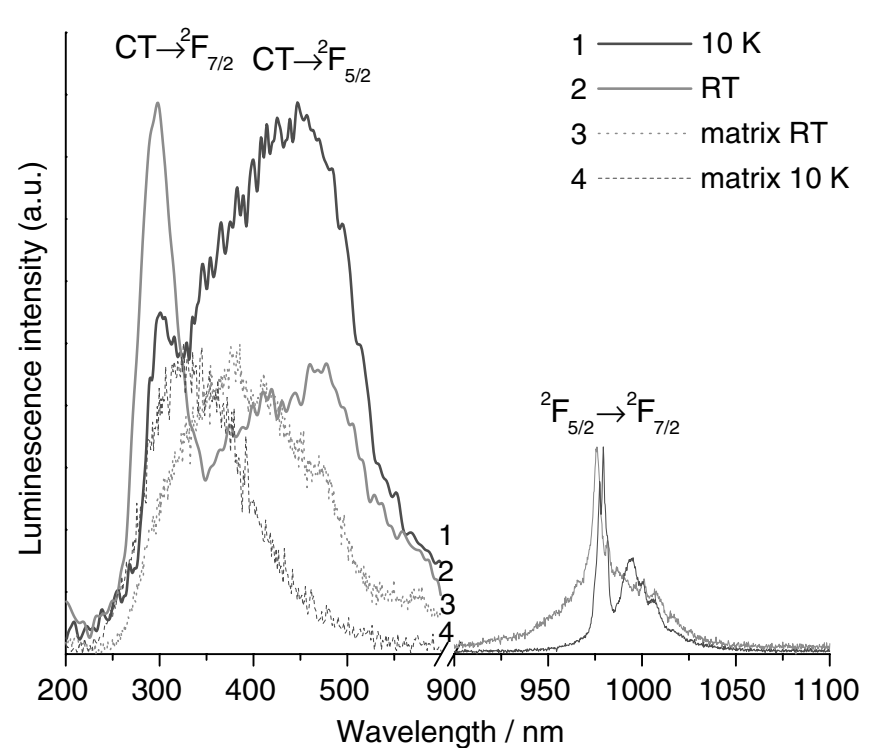

Fig. 7. The emission spectra of the $\mathrm{Na}_{3} \mathrm{Y}\left(\mathrm{PO}_{4}\right)_{2}$ host lattice and of $\mathrm{Na}_{3} \mathrm{Y}\left(\mathrm{PO}_{4}\right)_{2}$ doped with $10 \mathrm{~mol} \% \mathrm{Yb}^{3+}$ measured at 10 and $293 \mathrm{~K}$. Both have been recorded with excitation at $170 \mathrm{~nm}$.

\section{Summary}

A new type of the lutetium double phosphates sodium salt containing $\mathrm{Yb}^{3+}$ has been synthesised by a solid state reaction. The thermogravimetric analysis has allowed to determine the optimal conditions of heat treatments to obtain expected $\mathrm{Na}_{3} \mathrm{Lu}_{0.9} \mathrm{Yb}_{0.1}\left(\mathrm{PO}_{4}\right)_{2}$. Fig. 1a and $\mathrm{b}$ shows purity of the substrate (a) and the steps of the double phosphates synthesis (b). Detail analysis of the X-ray powder diffraction data allows to assume the structural modification of lutetium double phosphates sodium salt because the diffractograms of the $\mathrm{Na}_{3} \mathrm{Lu}\left(\mathrm{PO}_{4}\right)_{2}: \mathrm{Yb}^{3+}$ is close but not identical to that of the orthorhombic yttrium compounds. At the moment the crystal structure of $\mathrm{Na}_{3} \mathrm{Lu}_{0.9} \mathrm{Yb}_{0.1}\left(\mathrm{PO}_{4}\right)_{2}$ remains unknown but the details of the structure are under investigation.

The spectroscopic properties of the $\mathrm{Na}_{3} \mathrm{Lu}\left(\mathrm{PO}_{4}\right)_{2}: \mathrm{Yb}^{3+}$ and $\mathrm{Na}_{3} \mathrm{Y}\left(\mathrm{PO}_{4}\right)_{2}: \mathrm{Yb}^{3+}$ double phosphates have been investigated. The structural differences between them have been found. They are manifested in the splitting and the intensity values of the $\mathrm{Yb}^{3+}{ }^{2} \mathrm{~F}_{7 / 2} \rightarrow{ }^{2} \mathrm{~F}_{5 / 2}$ and ${ }^{2} \mathrm{~F}_{5 / 2} \rightarrow{ }^{2} \mathrm{~F}_{7 / 2}$ transitions for both types of the double phosphates. This could be caused by some disordering of the $\mathrm{Na}_{3} \mathrm{Lu}\left(\mathrm{PO}_{4}\right)_{2}$ : $\mathrm{Yb}^{3+}$ crystal structure. The superposition of the IR, absorption and emission spectra measured at $4 \mathrm{~K}$ and $293 \mathrm{~K}$ allows to assign some vibronic components which correspond to the IR active modes. These components can be seen in both the absorption and emission spectra obtained at low temperatures.

An excitation of the $\mathrm{Yb}^{3+}$-doped sodium double phosphates in the VUV region ( $170 \mathrm{~nm}$ ) induces the broad emission consisting of two bands with maxima at ca. 290 and $420 \mathrm{~nm}$. The energy difference between these bands could be assigned to the transitions from the charge transfer state to ${ }^{2} \mathrm{~F}_{7 / 2}$ and ${ }^{2} \mathrm{~F}_{5 / 2}$ of $\mathrm{Yb}^{3+}$. The fundamental emission of the $\mathrm{Yb}^{3+} \mathrm{f}-\mathrm{f}$ transition has also been observed with the excitation in the VUV region at $10 \mathrm{~K}$ as well as at RT. The number of lines detected in the absorption and emission spectra of $\mathrm{Na}_{3} \mathrm{Y}\left(\mathrm{PO}_{4}\right)_{2}: \mathrm{Yb}^{3+}$ a $4 \mathrm{~K}$ may suggest the existence of the two lanthanide sites in the structures of these compounds. To confirm this it is necessary to measure the $\mathrm{Yb}^{3+}$ selective excitation emission spectra by using a Ti/shapphire laser as an excitation source. On the basis of the emission and absorption spectra obtained at low temperatures the energy level schemes have been proposed.

\section{Acknowledgements}

The authors would like to thank professor G. Meyer (University of Cologne, Germany) for the measurements of the X-ray powder diffraction. Experiments performed in HASYLAB DESY have been supported by the European Community (II-05-106 EC).

\section{References}

[1] A. Bensalah, Y. Guyot, A. Brenier, H. Sato, T. Fukuda, G. Boulon, J. Alloys Comp. 380 (2004) 15.

[2] E. Nakazawa, Chem. Phys. Lett. 56 (1978) 161.

[3] R.S. Raghavan, Phys. Rev. Lett. 78 (1997) 3618.

[4] L. van Pieterson, M. Heeroma, E. de Heer, A. Meijerink, J. Lumin. 91 (2000) 177.

[5] B. Finke, L. Schwarz, P. Günter, M. Kraas, M. Joppien, S. Becker, J. Lumin. 60/61 (1994) 975.

[6] L. Schwarz, B. Finke, M. Kloss, A. Rohmann, U. Sasum, D. Haberland, J. Lumin. 72-74 (1997) 257.

[7] Z.S. Chao, C. Perent, G. Le Flem, P. Hagenmmuller, J. Solid State Chem. 82 (1989) 255.

[8] R. Salmon, C. Parent, M. Vlasse, G. Le Flem, Mater. Res. Bull. A3 (1978) 439.

[9] R. Salmon, C. Parent, A. Berrada, R. Brochu, A. Daoudi, M. Vlasse, G. Le Flem, C. R. Acad. Sci. Paris 280 (1975) 805.

[10] K. Okada, J. Ossaka, Acta Cryst. B 36 (1980) 919.

[11] S. Areva, J. Holsa, M. Kloss, M. Lahtinen, R.-J. Lamminmaki, M. Lastusaari, L. Schwarz, J. Valkonen, Mat. Sci. Forum 378-381 (2001) 644.

[12] W. Szuszkiewicz, B. Keller, M. Guzik, T. Aitasalo, J. Niittykoski, J. Holsa, J. Legendziewicz, J. Alloys Comp. 341 (2002) 297.

[13] T. Aitasalo, M. Guzik, W. Szuszkiewicz, J. Holsa, B. Keller, J. Legendziewicz, J. Alloys Comp. 380 (2004) 405.

[14] M. Guzik, T. Aitasalo, W. Szuszkiewicz, J. Holsa, B. Keller, J. Legendziewicz, J. Alloys Comp. 380 (2004) 368.

[15] M. Laroche, S. Girard, R. Mancorgé, M. Bettinelli, R. Abdulsabirov, V. Semasko, Opt. Mater. 22 (2003) 147.

[16] J. Legendziewicz, T. Glowiak, G. Oczko, D.C. Ngoan, J. LessCommon Met. 125 (1986) 45.

[17] J. Legendziewicz, Wiad. Chem. 42 (1988) 605.

[18] G. Boulon, L. Laversenne, C. Goutaudier, Y. Guyot, M.T. CohenAdad, J. Lumin. 102-103 (2003) 417.

[19] I.A. Kamenskikh, N. Guerassimova, C. Dujardin, N. Garnier, G Ledoux, C. Pedrini, M. Kirm, A. Petrosyan, D. Spassky, Opt. Mater. 24 (2003) 267.

[20] A. Voloshinovskii, I. Sol'skii, G. Stryganyuk, Yu. Romanyshyn, Z. Khapko, O. Antoniak, HASYLAB Annual Report 2003.

[21] L. van Pieterson, A. Meijerink, J. Alloys Comp. 300-301 (2000) 426.

[22] C.K. Jørgensen, Progr. Inorg. Chem. 12 (1970) 161. 